\title{
Erratum: Hosokawa, R., et al. Associations between Healthcare Resources and Healthy Life Expectancy: A Descriptive Study across Secondary Medical Areas in Japan. Int. J. Environ. Res. Public Health 2020, 17,6301
}

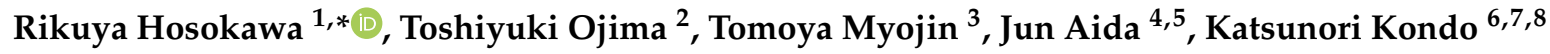 \\ and Naoki Kondo 9,10 \\ 1 Department of Human Health Sciences, Graduate School of Medicine, Kyoto University, \\ Kyoto 606-8507, Japan \\ 2 Department of Community Health and Preventive Medicine, Hamamatsu University School of Medicine, \\ Shizuoka 431-3192, Japan; ojima@hama-med.ac.jp \\ 3 Department of Public Health, Health Management and Policy, Nara Medical University, Nara 634-8521, \\ Japan; motoya1014@gmail.com \\ 4 Department of Oral Health Promotion, Graduate School of Medical and Dental Sciences, Tokyo Medical and \\ Dental University, Tokyo 113-8549, Japan; junaida916@gmail.com \\ 5 Division for Regional Community Development, Liaison Center for Innovative Dentistry, Graduate School \\ of Dentistry, Tohoku University, Miyagi 980-8575, Japan \\ 6 Center for Preventive Medical Sciences, Chiba University, Chiba 263-8522, Japan; kkondo@kkondo.net \\ 7 Center for Well-being and Society, Nihon Fukushi University, Aichi 470-3295, Japan \\ 8 Center for Gerontology and Social Science, National Center for Geriatrics and Gerontology, \\ Aichi 474-8511, Japan \\ 9 Department of Health and Social Behavior, School of Public Health, The University of Tokyo, \\ Tokyo 113-0033, Japan; nkondo@m.u-tokyo.ac.jp \\ 10 Department of Health Education and Health Sociology, School of Public Health, The University of Tokyo, \\ Tokyo 113-0033, Japan \\ * Correspondence: hosokawa.rikuya.4r@kyoto-u.ac.jp
}

Received: 24 September 2020; Accepted: 13 October 2020; Published: 16 October 2020

Incorrect:

$\leq 0$ th percentile 

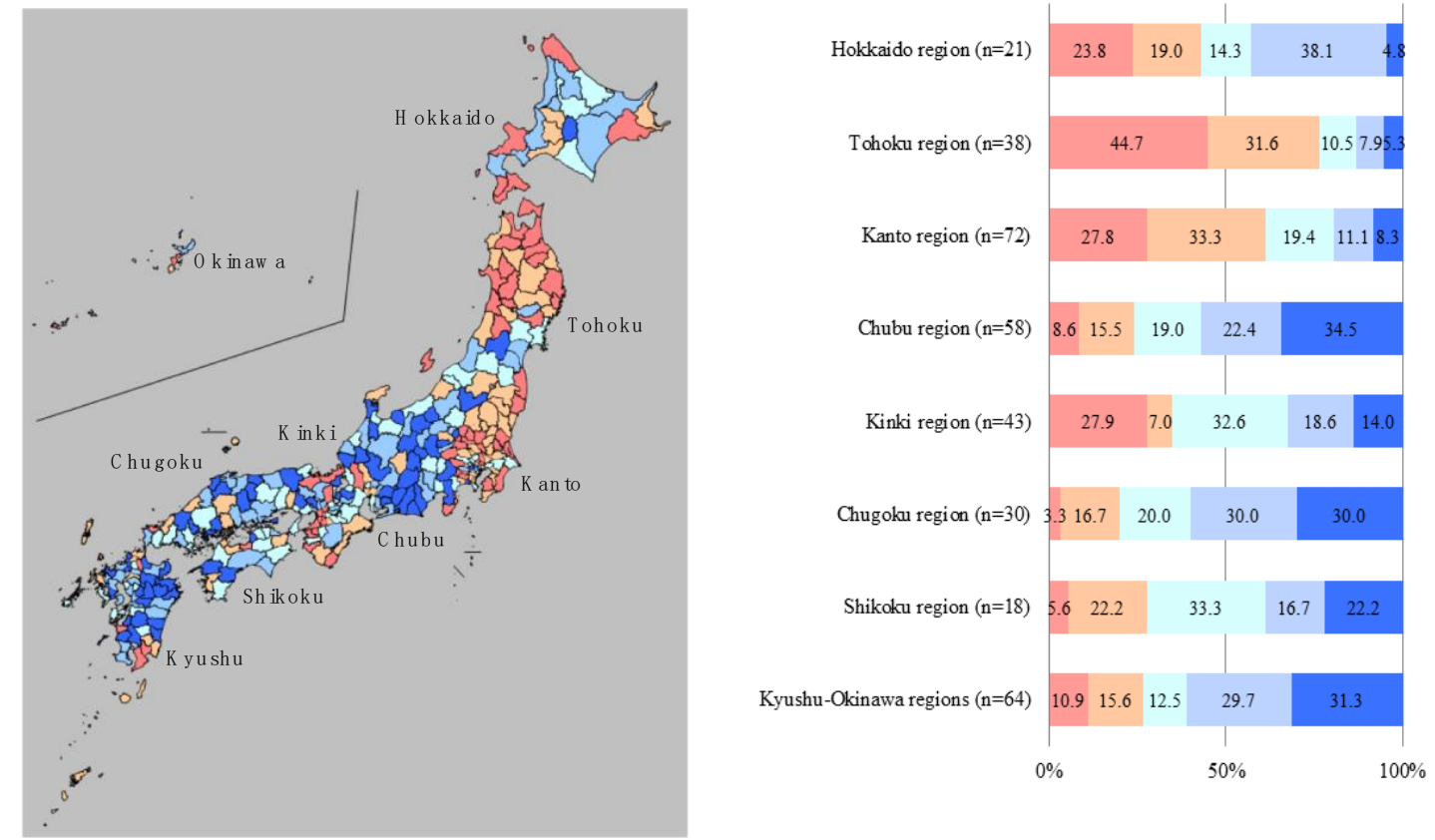

$\leq 83.25$ ( $\leq$ th percentile) $\leq 84.28$ ( $\leq 80$ th percentile)

\section{Correct:}

$\leq 20$ th percentile
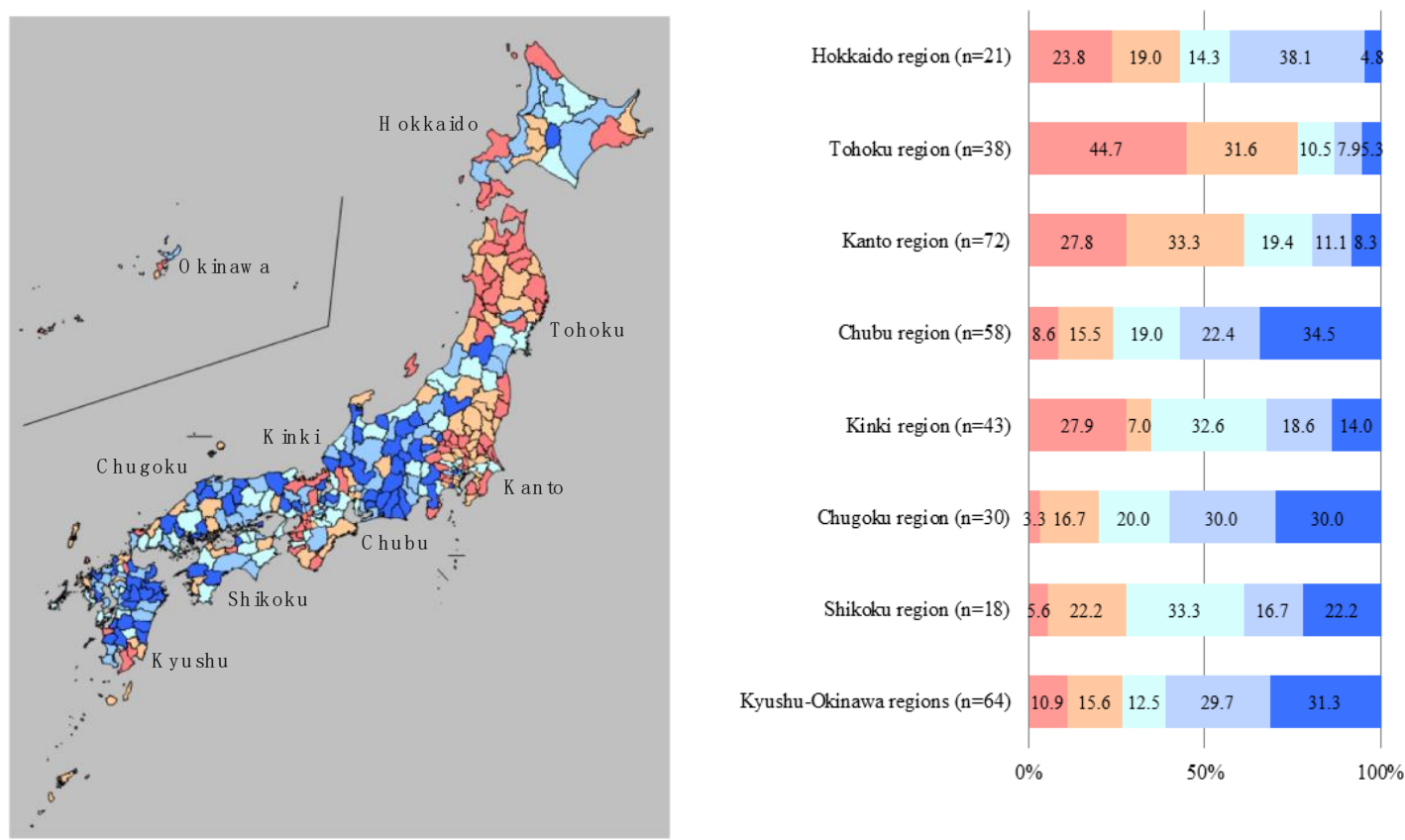

$\leq 83.25$ ( $\leq 20$ th percentile) $\leq 84.28$ ( $\leq 80$ th percentile)

We apologize for any inconvenience caused to readers or authors by these changes. The article will be updated and the original will remain available on the article webpage. 


\section{Reference}

1. Hosokawa, R.; Ojima, T.; Myojin, T.; Aida, J.; Kondo, K.; Kondo, N. Associations between Healthcare Resources and Healthy Life Expectancy: A Descriptive Study across Secondary Medical Areas in Japan. Int. J. Environ. Res. Public Health 2020, 17, 6301. [CrossRef]

Publisher's Note: MDPI stays neutral with regard to jurisdictional claims in published maps and institutional affiliations.

(C) 2020 by the authors. Licensee MDPI, Basel, Switzerland. This article is an open access article distributed under the terms and conditions of the Creative Commons Attribution (CC BY) license (http://creativecommons.org/licenses/by/4.0/). 